\title{
Sociodemographic profile of orofacial cleft patients in India: A hospital-based study
}

Aim: Long-term health of the stomatognathic system as well as esthetic aspects is the therapeutic goals in patients with orofacial clefts (OFCs). The aim of this study was to assess the sociodemographic profile of patients with OFCs in India. Materials and Methods: The study group consisted of 108 cleft patients. Subjects were divided into three groups. Group 1: Patients with cleft lip (CL), Group 2: Subjects with cleft palate and Group 3: Subjects with CL alveolus and palate (CLAP). A pretested interviewer administered questionnaire was used. Socioeconomic status (SES) was assessed using Pareek's scale for the rural population and Kuppuswamy's scale for the urban population. Results: Among the 108 study subjects, 69 (63.9\%) were males, and $39(36.1 \%)$ were females. $64(59.2 \%)$ study subjects were residing in rural areas, and $44(40.8 \%)$ were residing in urban areas. $29(26.80 \%)$ from rural areas and $21(19.50 \%)$ from the urban areas had a family income below Rs. 5001-10000. In rural areas, 47 (73.40\%) study subjects belonged to the middle class and $17(26.60 \%)$ study subjects belonged to the lower middle class. In urban areas, $20(45.50 \%)$ study subjects belonged to the middle class and $24(54.50 \%)$ study subjects belonged to the lower class. Conclusion: Most of the study subjects in rural areas belonged to middle SES, whereas in urban areas belonged to lower SES.

Key words: Cleft lip, cleft patients, orofacial cleft, socioeconomic status

\section{Nagappan Nagappan, Joseph John ${ }^{1}$}

Department of Public Health Dentistry, Chettinad Dental College and Hospital, Kelambakkam, Chennai, Tamil Nadu, 'Department of Public Health Dentistry, Saveetha Dental College and Hospital, Chennai, Tamil Nadu, India

\section{Address for the Correspondence:}

Dr. N. Nagappan,

Department of Public Health

Dentistry, Chettinad Dental

College and Hospital, Rajiv

Gandhi Salai, Kelambakkam, Chennai - 603 103,

Tamil Nadu, India.

E-mail: nagappan.dent@gmail.com

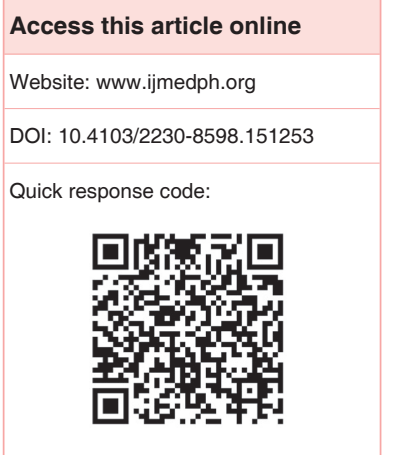

\section{INTRODUCTION}

Socioeconomic status (SES) is most often characterized as the hierarchical rank of an individual or family in a particular community or society. SES spreads across a continuum stratified by social and economic resources. The social indicators of SES include intangible characteristics such as educational attainment, occupational prestige, authority, group associations, place of residence, and community standing. Some primary economic indicators of SES are tangible assets and include money, wealth, home ownership, pension plans, and property ownership. ${ }^{[1]}$

Decades of research have shown SES to be consistently and significantly correlated with occupational attainment, health status, and social capital. The study of SES is most prominent in sociology, which broadly and most often examines relationships between social and economic class and educational inequality, health, residential segregation, and race. Furthermore, social science researchers in general have used SES as a construct to disaggregate inequalities across racial and ethnic groups. ${ }^{[1]}$ Epidemiological studies have shown that health and diseases are not equally distributed in social classes. Individuals in the upper social classes have a longer life expectancy and better health and nutritional status than those in the lower social classes. ${ }^{[1]}$

The cleft of lip and alveolus, hard and soft palate are the most common congenital abnormalities of the craniofacial structure. Worldwide incidence of the cleft lip (CL) and palate is 1 in $600(1: 600) \cdot{ }^{[2]}$ The overall worldwide prevalence of the CL with or without a cleft palate (CP) was 9.92/10,000. The prevalence of the CL was 3.28/10,000, and that of the CL and palate was $6.64 / 10,000 .{ }^{[3]}$

As a consequence, breathing, appearance, dentition, dental occlusion, facial growth, speech and hearing can all be affected leading to psychosocial implications. ${ }^{[4]}$ It may not be the end of life, but for children with cleft problem, the problem goes beyond the obvious disfigurement of the face and extends to repeated infections, social stigma, and mental impairment that affect the speech, hearing, and teeth 
formation. These children are teased about their cleft-related features such as speech, teeth, and lip appearance and lose self-confidence. ${ }^{[5]}$

India is one of the many regions of the world where documentation of the rates of birth anomalies is incomplete. Reliable and complete record of statistics is difficult because of the infrastructure and due to the association of craniofacial anomalies. It is known, however, that in many parts of India the parents of a child born with a cleft have no access to counseling on the care and treatment of their children. CL and palate may be perceived to be a life-threatening abnormality, and there may be little awareness of the fact that clefts can be surgically repaired with considerable success both esthetically and functionally. The lack of knowledge and resources results in unacceptable delays in seeking and receiving adequate medical care, due to which, many infants with OFCs die of malnutrition or infection. This grim situation is further compounded by (a) failure of healthcare authorities to recognize craniofacial anomalies as a notifiable disease, and (b) the World Health Organization in their continuing use of the diagnostic rather than functional classification of clefts. Both these perceived problems are, however, currently being addressed. ${ }^{[2]}$

The assessment of SES of these children will provide an opportunity to assess their influence of socioeconomic factors on their oral health. However, there are not many studies about the sociodemographic profile of patients with OFCs in India. Hence, the current study was planned to assess the SES of OFC patients in India.

\section{MATERIALS AND METHODS}

\section{Study design}

A cross-sectional descriptive study.

\section{Study area}

A hospital-based study (Smile Train Center, Department of Plastic surgery, Sri Ramachandra Medical College and Hospital, Sri Ramachandra University, Chennai).

\section{Study population}

Patients receiving care at the outpatient ward of the Department of Plastic Surgery, Sri Ramachandra Medical College and Hospital, Sri Ramachandra University, Chennai, formed the study population.

\section{Inclusion criteria}

- $\quad$ Subjects who reported to Smile Train Center, Chennai with OFCs.

- $\quad$ Subjects $<18$ years of age who had reported with their parents and willing to participate.

- $\quad$ Subjects $>18$ years of age who reported and who were willing to participate.

\section{Exclusion criteria}

- $\quad$ Subjects/Parents of children $<18$ years, who are not willing to give informed consent.

\section{Sampling methodology}

$N=108$ A convenience sampling technique was employed. Outpatients reporting to the hospital during the period of the survey (i.e., December 2012) and those who met the inclusion/exclusion criteria formed the study population.

\section{Approval and informed consent}

Ethical approval was obtained from the Institutional Ethics Committee of Saveetha University and Institutional Review Boards of Sri Ramachandra University. Informed consent was obtained from parents or guardian of study participants.

\section{Scheduling}

Data collection were scheduled for a period of 1-month from December 1, 2012 to December 31, 2012.

\section{Statistical analysis}

The data collected were analyzed and tested for significance using statistical software package, SPSS software for windows (version 17.0 SPSS Inc, Chicago, IL 60606-6412). Frequency tables were computed.

Pearson Chi-square test was used to find a relationship between the level of literacy in urban and rural population.

\section{Survey instrument}

A pretested interviewer administered questionnaire was used. Assessment of socio economic status is an inherent part of various community-based and many hospital-based studies, which seek to the study the effect of socio economic status on different disease states. SES was assessed using Pareek's scale for rural population ${ }^{[6]}$ and Kuppuswamy's scale for urban population. ${ }^{[7]}$

\section{RESULTS}

Table 1 depicts the distribution of study subjects based on age and gender. The study sample consisted of 108 study subjects. $69(63.9 \%)$ were males and $39(36.1 \%)$ were females. The age group of study subjects ranged from 6 to 30 years. $43(39.8 \%)$ study subjects were aged 6-11 years, 24 (22.2\%) study subjects were aged $12-16$ years, $23(21.3 \%)$ study subjects were aged $17-21$ years, $11(10.2 \%)$ study subjects were aged $22-26$ years, $7(6.5 \%)$ study subjects were aged 27-30 years.

\begin{tabular}{|c|c|c|c|}
\hline \multirow[t]{2}{*}{ Age in years } & Male & Female & Total \\
\hline & $n(\%)$ & $n(\%)$ & $n(\%)$ \\
\hline $6-11$ & $27(39.2)$ & $16(41.0)$ & $43(39.8)$ \\
\hline $12-16$ & $17(24.6)$ & $7(18.0)$ & $24(22.2)$ \\
\hline $17-21$ & $13(18.8)$ & $10(25.7)$ & $23(21.3)$ \\
\hline $22-26$ & $7(10.2)$ & $4(10.2)$ & $11(10.2)$ \\
\hline $27-30$ & $5(7.2)$ & $2(5.1)$ & 7 (6.5) \\
\hline Total & 69 (63.9) & 39 (36.1) & 108 (100) \\
\hline
\end{tabular}


Figure 1 depicts the distribution of study subjects based on gender and cleft types. Among the CL group, 23 (21.3\%) were males, and $13(12 \%)$ were females. Among the CP group, 25 (23.3\%) were males and $11(10.1 \%)$ were females and among the CL alveolus and palate (CLAP) group, 21 (19.4\%) were males, and 15 (13.9\%) were females.

Table 2 depicts the distribution of study subjects based on cleft types and location. $64(59.2 \%)$ study subjects were residing in rural areas, and 44 (40.8\%) were residing in urban areas. Among the CL group, $20(31.2 \%)$ study subjects were residing in rural areas and $16(36.4 \%)$ were residing in urban areas. Among the CP group, 20

\begin{tabular}{|c|c|c|c|}
\hline \multirow[t]{2}{*}{ Cleft types } & Rural & Urban & Total \\
\hline & $n(\%)$ & $n(\%)$ & $n(\%)$ \\
\hline Cleft lip & $20(31.2)$ & $16(36.4)$ & $36(33.3)$ \\
\hline Cleft palate & $20(31.2)$ & $16(36.4)$ & $36(33.3)$ \\
\hline Cleft lip alveolus and palate & $24(37.6)$ & $12(27.2)$ & $36(33.3)$ \\
\hline Total & $64(59.2)$ & $44(40.8)$ & $108(100)$ \\
\hline
\end{tabular}

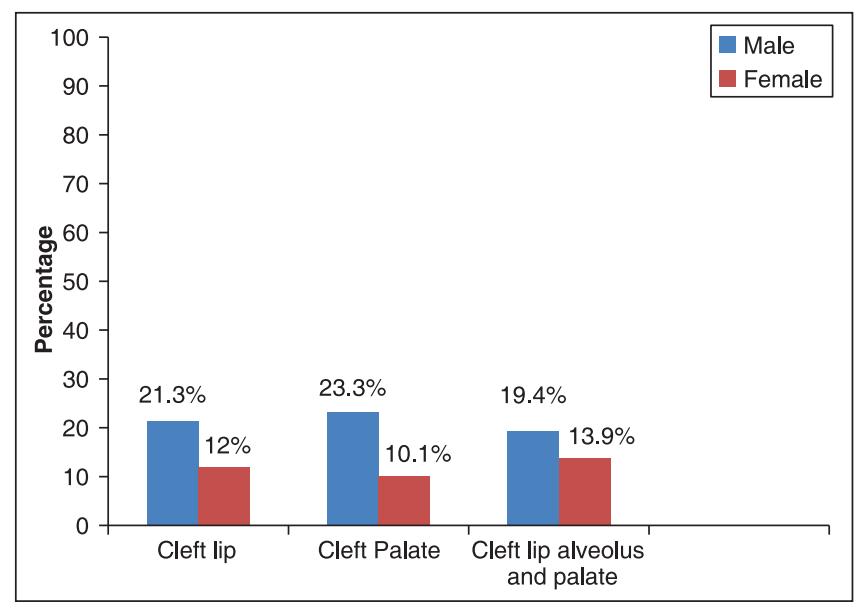

Figure 1: Distribution of study subjects based on gender and cleft types

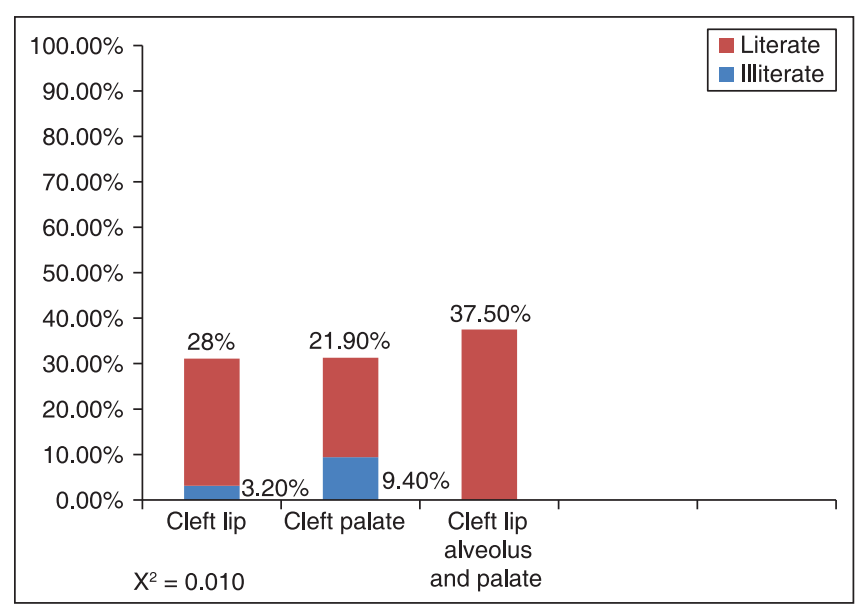

Figure 3: Distribution of study subjects based on level of literacy in rural population $\mathrm{X}^{2}=0.010$
$(31.2 \%)$ study subjects were residing in rural areas and $16(36.4 \%)$ were residing in urban areas. Among the CLAP group, 24 (37.6\%) study subjects were residing in rural areas and $12(27.2 \%)$ were residing in urban areas.

Figure 2 depicts the distribution of study subjects based on religion. Among the 108 study subjects, Hindus constituted 74 (68.6\%), Christians constituted 17 (15.7\%) and Muslims constituted $17(15.7 \%)$

Figure 3 depicts the distribution of study subjects based on the level of literacy in a rural population. Among the CL group, illiterates were $2(3.20 \%)$ and literates were 18 (28.1\%). Among the CP group, illiterates were 6 (9.4\%) and literates were 14 (21.90\%). Among the CLAP group, none of them was illiterates, and literates were $24(37.50 \%)$. Pearson Chi-square test was performed, and the relationship between the levels of literacy in a rural population was found to be statistically significant.

Figure 4 depicts the distribution of study subjects based on the level of literacy in urban population. Among the CL group, none of them was illiterates, and literates were 16 (36.4\%). Among the

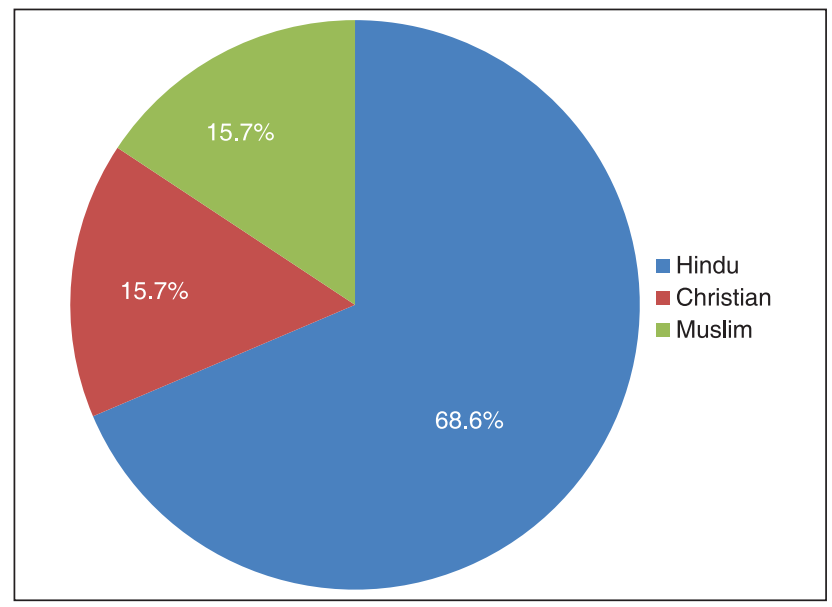

Figure 2: Distribution of study subjects based on religion

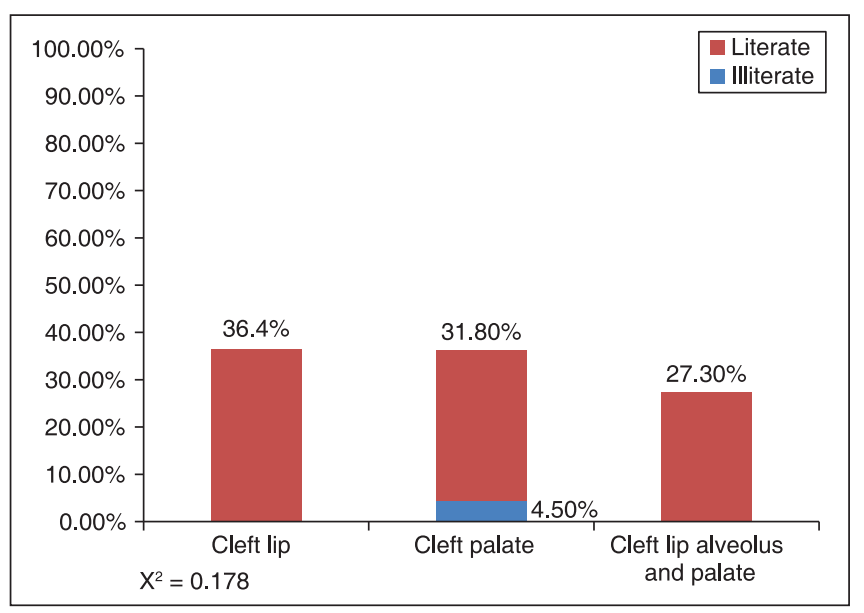

Figure 4: Distribution of study subjects based on level of literacy in urban population $\mathrm{X}^{2}=0.178$ 
CP group, illiterates were 2 (4.50\%) and literates were 14 (31.80\%). Among the CLAP group, none of them was illiterates, and literates were $12(27.30 \%)$. Pearson Chi-square test was performed, and the relationship between the levels of literacy in urban population was found to be not statistically significant.

Figure 5 depicts the distribution of study subjects based on family income and location. Among the 108 study subjects, $24(22.20 \%)$ from rural areas and $8(7.40 \%)$ from the urban areas had a family income below Rs. 5000. 29 (26.80\%) from rural areas and $21(19.50 \%)$ from the urban areas had a family income below Rs. 5001-10000. 11 (10.20\%) from rural areas and $15(13.9 \%)$ from the urban areas had a family income above Rs. 10001.

Figure 6 depicts the distribution of study subjects according to socio-economic status in urban population. The SES based on Kuppuswamy's classification showed that none of them were belonged to upper class, $20(45.50 \%)$ study subjects belonged to the middle class and $24(54.50 \%)$ study subjects belonged to the lower class.

Figure 7 depicts the distribution of study subjects according to socioeconomic status in a rural population. The SES based on Pareek's classification showed that none of them was belonged to upper class, $47(73.40 \%)$ study subjects belonged to the middle class and $17(26.60 \%)$ study subjects belonged to the lower middle class.

\section{DISCUSSION}

A child with an oral cleft is born with a unique challenge to fight against various problems relating to the appearance, dental arch dimensions, growth of the face and speech development. Their speech abilities are reported to be inferior to those of the healthy subjects, and they have been stated to misarticulate frequently the dental consonants. The present study was planned to record the sociodemographic profile of patients with OFCs in a hospital setting. This study was conducted at Smile Train Center, Sri Ramachandra University, Chennai, which is a premier hospital to provide treatments for orofacial patients by multidisciplinary teams such as general medicine, general surgery, pediatrician, plastic surgeon, orthodontist, pedodontics, etc.

All orofacial patient with parents/guardians who reported for treatment during this study period (i.e., December 2012) were included in the study. After a clinical diagnosis, a total of 108 orofacial patients formed the study population with age ranging from 6 to 30 years. Among the 108 study subjects, 69 (63.9\%) were males, and 39 (36.1\%) were females. Males had a higher prevalence of orofacial anomalies when compared with females. This was in accordance with the study by Murthy et al. and McLeod et al. ${ }^{[8,9]}$

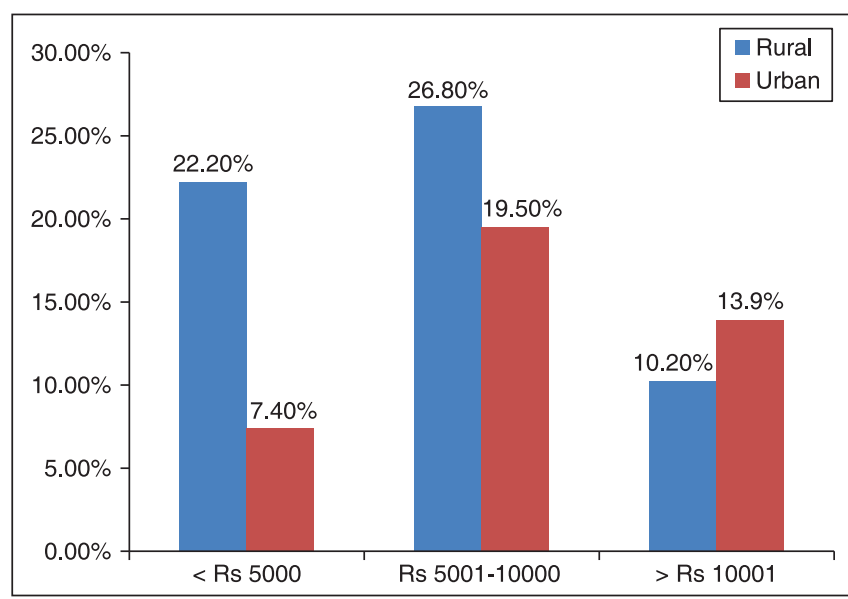

Figure 5: Distribution of study subjects based on family income and location

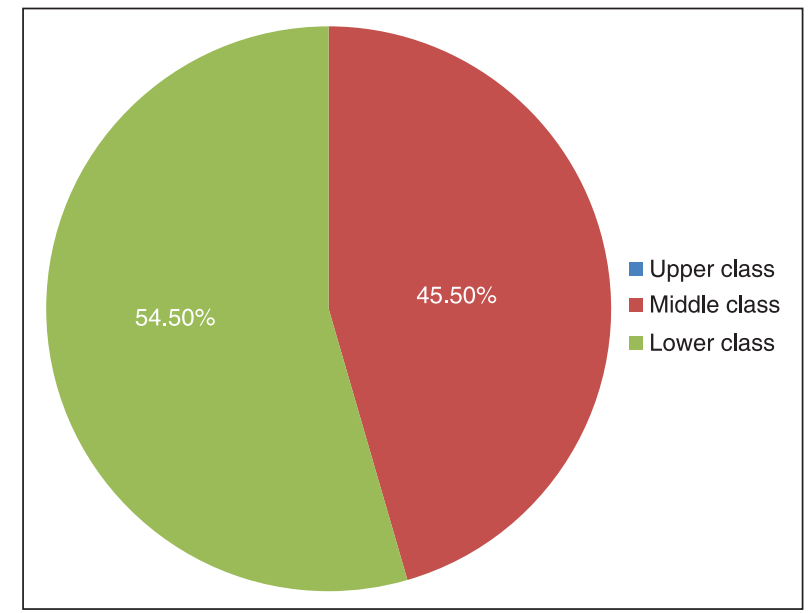

Figure 6: Distribution of study subjects according to socioeconomic status (Urban)

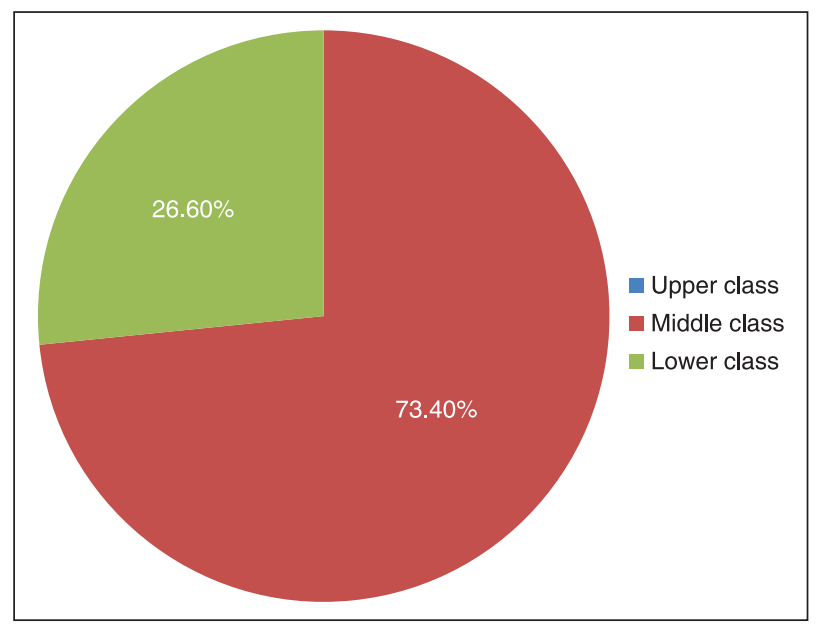

Figure 7: Distribution of study subjects according to socioeconomic status (Rural)

The study subjects were from both rural 64 (59.2\%) and urban $44(40.8 \%)$ areas, whereas in the study conducted by AcuñaGonzález et al. $80(19.2 \%)$ of study subjects were from rural 
areas and $336(80.8 \%)$ of study subjects were from urban areas. $^{[10]}$

In the current study, majority of study subjects belonged to 6-11 years $43(39.8 \%)$ followed by 12-16 years $24(22.2 \%), 17-21$ years 23 (21.3\%), 22-26 years $11(10.2 \%)$, and $27-30$ years $7(6.5 \%)$.

The study subjects belonged to middle SES class and lower SES class from rural and urban area, whereas in the study by Olasoji et al. majority of study subjects belonged to lower SES class. ${ }^{[1]}$ There might exist a correlation between SES of family and risk of having a child with CL/palate in Indian population. Even though, they are not directly related, but probably due to maternal nutrition status. The study by Habib (1978) reveals that the nutrition of a pregnant woman was probably a link between the social class and the incidence of CL/CP. ${ }^{[12]}$

In the current study, most of the study subjects were semiskilled workers. In urban area $52.2 \%$ and in rural area 61\%, whereas in the study conducted by Olasoji et al. $21.5 \%$ of study subjects were semiskilled workers. ${ }^{[11]}$

In both rural and urban population study subjects, majority (i.e.,) $26.8 \%$ and $19.5 \%$ had family income of Rs. 5001 to Rs. 10000. Whereas in the study conducted by Rodrigues et al. in south Brazilian regions per capita income was $137.46 \$$ (Rs. 8800). ${ }^{[13]}$

The percentage of illiterates was low in both rural and urban population (i.e) $12.6 \%$ and $4.5 \%$ respectively. The difference in a relationship between education and location was found to be statistically significant. However the study conducted by Olasoji et al. $83.1 \%$ of study subjects parents were illiterates. ${ }^{[11]}$

\section{CONCLUSION}

Identifying occupation, income and education in OFC patients can provide a useful "sign spot" indicating inequalities that need to be addressed by policy makers and the broader community through allocation of resources.

\section{REFERENCES}

1. Park K. Textbook of Preventive and Social Medicine. $19^{\text {th }}$ ed. New Delhi: Bhanot Publishers; 2006.

2. Mossey P, Little J. Addressing the challenges of cleft lip and palate research in India. Indian J Plast Surg 2009;42 Suppl:S9-18.

3. IPDTOC Working Group. Prevalence at birth of cleft lip with or without cleft palate: Data from the International Perinatal Database of Typical Oral Clefts (IPDTOC). Cleft Palate Craniofac J 2011;48:66-81.

4. LaRossa D. Cleft lip and palate. In: Schwartz MW, Curry TA, Sargurt AJ, editors. Text Book of Pediatric Primary Care (Problem Oriented Approach). $3^{\text {rd }}$ ed. Maryland Heights, Missouri: Mosby; 1997. p. 833-4.

5. Hunt O, Burden D, Hepper P, Johnston C. The psychosocial effects of cleft lip and palate: A systematic review. Eur J Orthod 2005;27:274-85.

6. Pareek U, Trivedi G. Manual of Socioeconomic Status (Rural). New Delhi: Manasayan Publishers; 1995.

7. Kuppusamy B. Manual of Socioeconomic Status (Urban). New Delhi: Manasayan Publishers; 1981.

8. Murthy ST, Dhanuja RJ, Diwakar S, Vernekar NV, Lodaya R. Prevalence of dental caries and oral hygiene practices in children with cleft lip and/or palate. Int J Contemp Dent 2010;1:12-7.

9. McLeod NM, Urioste ML, Saeed NR. Birth prevalence of cleft lip and palate in Sucre, Bolivia. Cleft Palate Craniofac J 2004;41:195-8.

10. Acuña-González G, Medina-Solís CE, Maupomé G, Escoffie-Ramírez M, Hernández-Romano J, Márquez-Corona Mde L, et al. Family history and socioeconomic risk factors for non-syndromic cleft lip and palate: A matched case-control study in a less developed country. Biomedica 2011;31:381-91.

11. Olasoji $\mathrm{HO}$, Adeosun $\mathrm{OO}$, Adesina AO. Socio-economic and cultural background of parents with non-syndromic cleft lip and/or palate children in northern Nigeria. Pak Oral Dent J 2005;25:139-43.

12. Habib Z. Factors determining occurrence of cleft lip and cleft palate. Surg Gynecol Obstet 1978;146:105-10.

13. Rodrigues K, Sena MF, Roncalli AG, Ferreira MA. Prevalence of orofacial clefts and social factors in Brazil. Braz Oral Res 2009;23:38-42.

How to cite this article: Nagappan N, John J. Sociodemographic profile of orofacial cleft patients in India: A hospital-based study. Int J Med Public Health 2015;5:35-9.

Source of Support: Nil, Conflict of Interest: None declared. 